

\section{II: Homosexualidad e Imagen}

como entrar en el armario. Ni una cosa ni la otra, o ambas o ambas a la vez; del mismo modo que los llamados "heteronormativos" han de salir o entrar de algún lugar para decir o decirse que son de determinada opción sexual.

Educar creemos que es un gesto generoso y una convicción que compartimos para conocernos y mejorar. Por ello, este monográfico sobre "Homosexualidad e imagen" se nutre de miradas de mujeres y hombres, para los menores y los adultos, para los de un lugar u otro del Atlántico... Para aprender, para seguir aprendiendo y de este modo tener capacidades de enseñar.

Sería muy difícil prescindir de alguno de estos artículos (de Brasil, Costa Rica, Chile y España -Madrid, Cataluña y Andalucía-), uno se termina "encariñando" con ellos y sus autores. Pero todos tienen en común un principio: el compromiso con la homosexualidad. Podemos coincidir, más o menos, con sus planteamientos pero son profundamente respetuosos; algo que los honra. Asimismo, desearíamos agradecer su colaboración a: FELGTB (Federación Estatal de Lesbianas, Gais, Transexuales y Bisexuales, España), ILGA (The International Lesbian, Gay, Bisexual, Trans and Intersex Association) y a los colectivos de Brasil, y más concretamente del Estado de Bahía, y a aquellas personas de Costa Rica, Colombia, España, del mundo árabe... Además de a los amigos del colectivo de Hombres por la Igualdad. En el número tres de la revista http (hachetetepé) hemos de disfrutarlo y entenderlo con los sentidos y no sólo con la razón. De lo contrario no conectaríamos con las intenciones, posiblemente, de los autores.

Víctor Amar (Universidad de Cádiz. España)

Antenor Rita Gomes (Universidad Estadual de Bahía. Brasil) 